\title{
Germination and vigour of polymer coated cotton seeds under different water holding capacities
} V. Manonmani
Department of Seed Science and Technology, Tamil Nadu Agricultural University,
Coimbatore-641 003 (Tamil Nadu), INDIA

\section{S. Ambika}

Department of Seed Science and Technology, Tamil Nadu Agricultural University, Coimbatore-641 003 (Tamil Nadu), INDIA

\section{S. Deepika}

Department of Seed Science and Technology, Tamil Nadu Agricultural University, Coimbatore-641 003 (Tamil Nadu), INDIA

\section{Bhaskaran}

Department of Seed Science and Technology, Tamil Nadu Agricultural University, Coimbatore-641 003 (Tamil Nadu), INDIA

*Corresponding author. E-mail: ambikasingaram@gmail.com

\begin{abstract}
The cotton seeds were coated with different polymers namely Genius coat 171 , Genius coat 172, Arcus, Myconate and Quick roots and evaluated for various physiological quality parameters at water holding capacities of $30,40,50,60,70$ and 80 per cent in sand medium along with untreated control seed. The seeds coated with Quick roots polymer recorded higher speed of germination (8.5), germination $(88 \%)$, root length $(10.35 \mathrm{~cm})$, shoot length $(10.80 \mathrm{~cm})$, dry matter production $\left(489.9 \mathrm{mg}^{2}\right.$ seedlings $\left.{ }^{-10}\right)$ and vigour index (1861), respectively over untreated control $(5.5,68,9.00,9.50,458.6$ and 1258 , respectively) under suboptimal moisture condition like 30 per cent water holding capacity. Cotton seeds coated with Quick roots can tolerate both high as well as low moisture content and produce better germination and seedling establishment.
\end{abstract}

Keywords: Cotton seed, Polymers, Seed coating, Water holding capacities

\section{Article Info}

DOI:10.31018/jans.v11i1.2026 Received: March 6, 2018

Revised: January 18, 2019

Accepted: February 13, 2019

\section{How to Cite}

Manonmani, $\mathrm{V}$. et al. (2019). Germination and vigour of polymer coated cotton seeds under different water holding capacities. Journal of Applied and Natural Science, 11(1): $126-129$

\section{INTRODUCTION}

Cotton is the world's leading natural fibre crop. It is called as "King of Fibres" and "White of Gold". India is the second largest cotton producer in the world. Gujarat is the major cotton producing states in India. Cotton crop not only provides fibre for the textile industry, but also plays a role in the feed and oil industries with its seed, rich in oil (18 $24 \%)$ and protein $(20-40 \%)$. Low crop productivity faced by Indian Agriculture is mainly because of poor soil health and various stress conditions. Though the high quality seeds are used for sowing in the field, it undergoes several stresses during the emergence and establishment leading to poor survival and reduced plant stand. Moisture content during germination leads reduced germination and poor seedlings growth (Chandra Kanta and Rao, 2014). One possible way to increase the plant water acquisition or drought tolerance is to use polymers as coating. The application of polymers to seed serves as an extra exterior shell in order to give the desired seed characteristics viz., quick water uptake and enhanced germination that would be beneficial for better emergence and establishment in the given condition (Taylor et al., 1998).

Polymer seed coating also increased the consumptive water use efficiency. It is due to increase in the rate of imbibition where the fine particles in the coating act as a 'wick' or moisture attracting material or perhaps to improve seed soil contact. The polymer coated corn seeds gave high seed germination than the uncoated seeds under water stress conditions (Schneider and Gupta, 1985). Therefore, the present study was undertaken to evaluate the germination and vigour of polymer coated cotton seeds under different water holding capacities.

\section{MATERIALS AND METHODS}

Genetically pure seeds of cotton (Akshay 65 F1Bt) were sent to the Integrated Coating Technology Pvt. Ltd., (INCOTEC), Ahmedabad, Gujarat for coating through machine with different polymers viz., Genius coat 171, Genius coat 172, Arcus, 
Myconate and Quick roots. The polymer coated cotton seeds along with untreated control were tested for physiological quality under various water holding capacities viz., 30, 40, 50, 60, 70 and 80 per cent. The different water holding capacities (WHC) were created by adding enough quantity of water to a known quantity of sand to achieve the saturation point (100 per cent water holding capacity) from that the other water holding capacities were arrived and seeds sown at different water holding capacities. Seedling quality characteristics such as germination (ISTA, 1999), speed of germination (Maguire, 1962), root length $(\mathrm{cm})$, shoot length $(\mathrm{cm})$, dry matter production of 10 seedlings (mg) and vigour index (Abdul-Baki and Anderson, 1973) were calculated. The data were analysed statistically adopting the procedure described by Panse and Sukhatme (1985).

\section{RESULTS AND DISCUSSION}

Cotton seed is susceptible to drought and seed germination is highly influenced by moisture status of the substrate. In order to get better establishment under very low and very high moisture status, polymer coating technology will be highly useful. The seeds coated with Quick roots polymer enhanced the speed of germination in all the water holding capacities and percent increase over control was $36,32,27,28,26$ and 26 under $30,40,50,60,70$ and 80 per cent water holding capacities, respectively (Fig. 1). The high speed of germination recorded at low moisture (30\% WHC) stress condition could be attributed to the faster

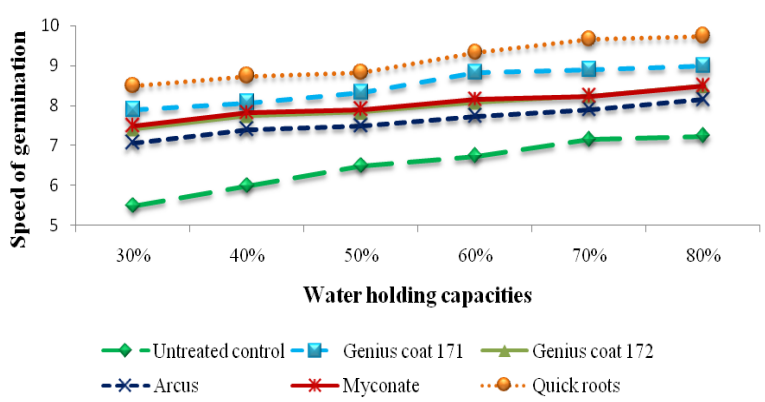

Fig.1. Effect of polymer coating on speed of germination of cotton seeds at different water holding capacities under laboratory condition

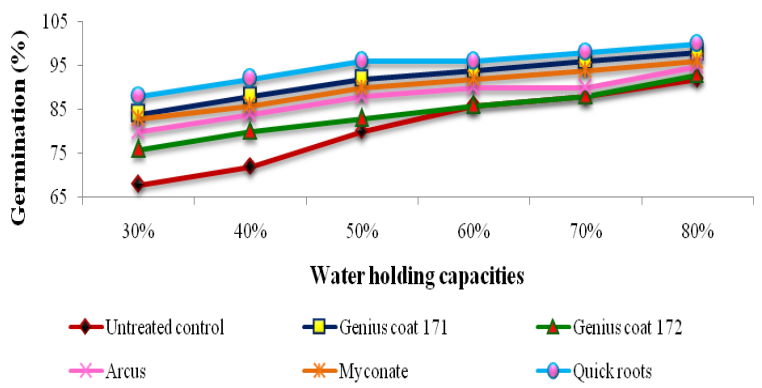

Fig.2. Effect of polymer coating on germination of cotton seeds at different water holding capacities under laboratory condition. germination of polymer coated seed. Irrespective of the water holding capacities, the polycoated seeds recorded higher speed of germination than the uncoated seeds which might be due to the hydrophilic property of the polycoat, absorbed available moisture and increased the water uptake that resulted in quicker radicle emergence. Henderson and Hensley (1987) reported that seed coating with polymer could provide protection against water stress and the hydrophilic polymers are mostly used to enhance the rate of water uptake and coating the seeds with hydrophilic polymer is a promising technique for maintaining a high water potential around the germinating seeds and thereby ensuring the soil water content not to fall below the critical level before germination.

The germination potential is considered to be an important parameter for assessing the potentiality of seeds. The seeds coated with Quick roots recorded higher germination at various water holding capacities. The increase over untreated control seed was $20,20,16,10,10$ and 8 per cent under $30,40,50,60,70$ and $80 \%$ water holding capacities, respectively (Fig. 2). The relative increase in germination due to Quick roots polymer coating might be attributed to the hydrophilic property of the polycoated seed which preserves the moisture and prolongs the moisture supply under stress condition. These polymers are having the capacity to absorb water about 100 to 1000 times of their weight from the surrounding rhizosphere which act as a local reservoir over a period of time and water from this reservoir is released gradually to the

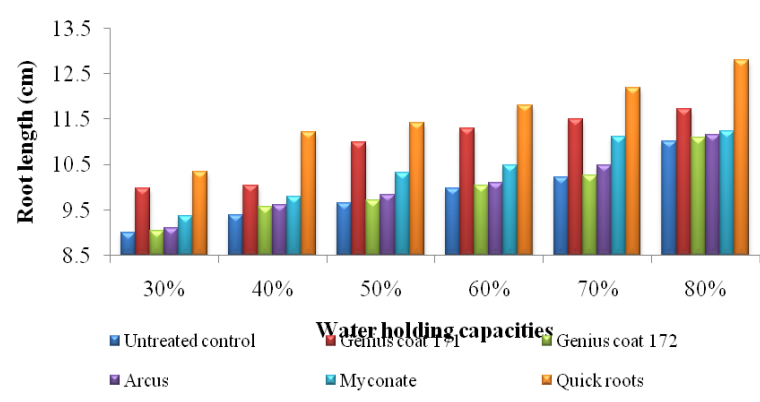

Fig.3.Performance of polymer coating on root length (cm) of cotton seeds at different water holding capacities under laboratory condition.

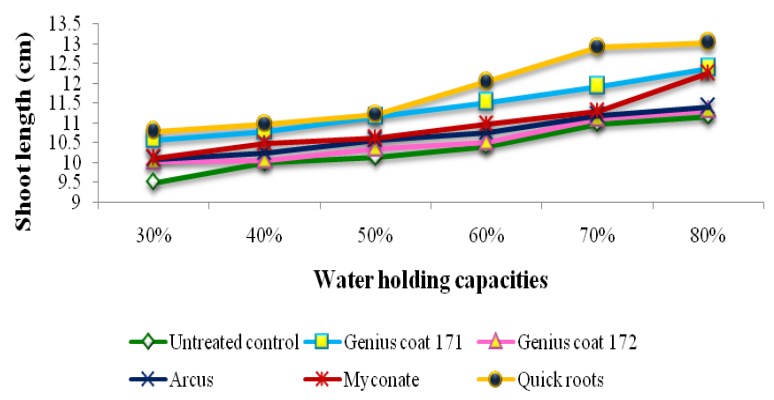

Fig. 4. Effect of polymer coating on shoot length (cm) of cotton seeds at different water holding capacities under laboratory condition 


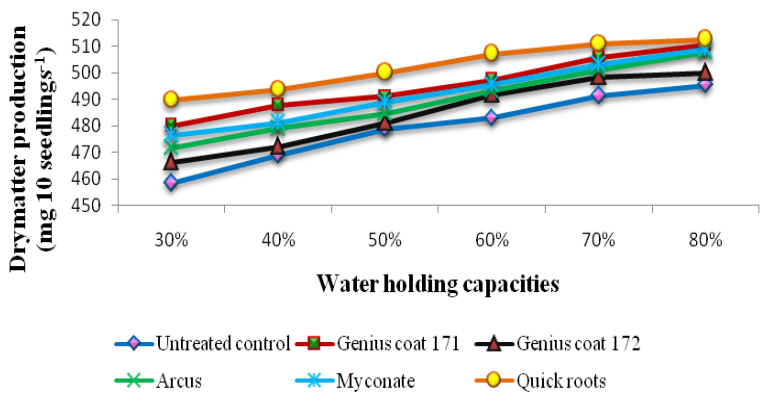

Fig 5. Performance of polymer coating on drymatter production ( $m g$ seedling $\mathrm{s}^{-10}$ ) of cotton seeds at different water holding capacities under laboratory condition

soil and thereby to plants based on need (lqbal and Srinivasan, 1987). Gaganpreet and Udai (2011) reported that polycoated seed was found to increase the seed germination under normal and water stress conditions in winter canola. Taylor and Kwiatkowski (2001) explained that film coating of snap beans with SB 2000 polymer at $0.5 \%$ greatly enhanced the germination in stress test. The results of the present study are in agreement with the findings of Baxter and Waters (1986) in sweet corn and cowpea and Renugadevi et al. (2009) in cluster bean.

The seeds coated with Quick roots polymer enhanced the root length $(\mathrm{cm})$ in all the water holding capacities and percent increase over untreated control was $13,16,15,15,16$ and 14 under $30,40,50,60,70$ and 80 per cent water holding capacities, respectively (Fig. 3). Similar the trend in shoot length $(\mathrm{cm})$ also. The seeds coated with Quick roots polymer shown highest shoot length in all the water holding capacities and percent increase over untreated control was $12,9,10,14$, 15 and 14 under 30, 40, 50, 60, 70 and 80 per cent water holding capacities, respectively (Fig. 4). The seeds coated with Quick roots polymer enhanced the dry matter production of 10 seedlings in all the water holding capacities and percent increase over untreated control was $6,5,4$, 5,4 and 3 under $30,40,50,60,70$ and 80 per cent water holding capacities, respectively(Fig. 5). Rajasekaran (2004) reported that brinjal hybrid seed $(\mathrm{COBH} 1)$ coated with polycoat $(3 \mathrm{~g})$ and halogen mixture $(3 \mathrm{~g})$ outperformed well in all the water holding capacities from 30 to $80 \%$. This indicated that polycoated seeds recorded higher germination and seedling length at two extreme moisture levels namely low and high moisture regimes. In the present study, the percent of vigour index increase over untreated control seed was 33,32 , 28, 24, 25 and 22 under 30, 40, 50, 60, 70 and $80 \%$ water holding capacities, respectively (Fig. $6)$. The increase in vigour index under moisture stress conditions might be attributed that the polymer coating could provide protection against water stress and help the seedling to grow faster and vigourous. The polymer coating had high water

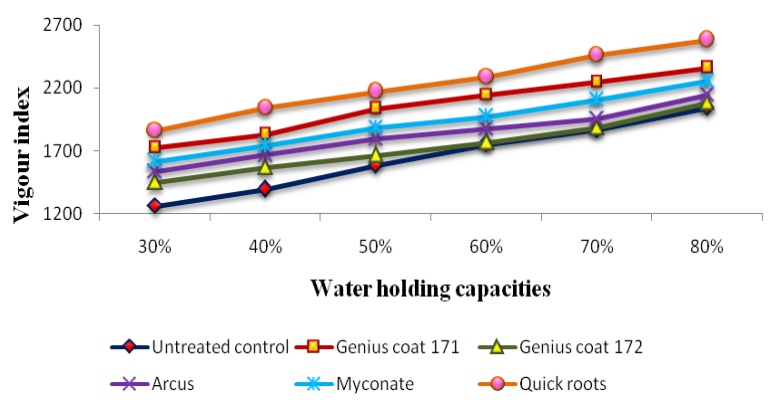

Fig. 6. Performance of polymer coating on vigour index of cotton seeds at different water holding capacities under laboratory condition.

conductivity and improved the seed water contact area which is important in water uptake of the seed and it expands on hydration and increases the area of liquid seed contact, a factor critical to imbibition (Handas and Ruso, 1974). Renugadevi et al. (2009) revealed that the maximum vigour index was observed due to polycoat along with bavistin had recorded 44 per cent improvement than the uncoated cluster bean seeds under moisture stress conditions.

\section{Conclusion}

The cotton seeds coated with quick roots polymer produced faster, uniform germination and high vigourus seedlings both under low and high moisture levels.

\section{ACKNOWLEDGEMENTS}

I am grateful to acknowledge INCOTEC Pvt. Ltd., Ahmedabad, Gujarat for providing me the junior research fellowship to pursue my research studies.

\section{REFERENCES}

1. Abdul-Baki, A. A. and Anderson. J. D. (1973). Vigour deterioration of soybean seeds by multiple criteria. Crop Sci., 13: 630-633.

2. Baxter, L. and Waters, L. (1986). Effect of a hydrophilic polymer seed coating on the field performance of sweet corn and cowpea. J. Amer. Soc. Hort. Sci., 111(1): 31-34.

3. Chandra Kanta and Rao, P. B. (2014). Effect of water stress on seed germination and seedling growth in six medicinal plant species in tarai region, Uttarakhand. The Bioscan, 9(4): 1383-1388.

4. Gaganpreet, K. and Udai, R. B. (2011). Effect of polymer and pesticide seed coatings on winter canola seed germination at various osmotic potentials. World J. of Agric. Sci., 7 (5): 591-598.

5. Handas, A. and Ruso, D. (1974). Water uptake by seeds as affected by water stress, capillary conductivity and seed soil water contact. Agron., 66: 643-647.

6. Henderson, J.C. and Hensley, L. (1987). Effect of a hydrophilic gel on seed germination of three tree species. Hort. Sci., 22: 450-452.

7. Iqbal, S. H. and Srinivasan, K. R. (1987). Invention intelligence. Division of technical services, NCL, pp. 382-385. 
8. ISTA. (1999). International Rules of Seed Testing. Seed Sci. and Technol., 27: 27-32.

9. Maguire, J. D. (1962). Speed of germination - Aid in selection and evaluation of seedling emergence and vigour. Crop Sci., 2: 176-177.

10.Panse, V. G. and Sukhatme, P. V. (1985). Statistical methods for Agricultural workers. ICAR, Publication, New Delhi: 327-340.

11.Rajasekaran, R. (2004). Investigation on seed production, enhancement and storage techniques in Brinjal hybrid COBH 1 (Solanum melongena L.) and its parental lines. Ph.D. Thesis, Tamil Nadu Agricultural University, Coimbatore.

12.Renugadevi, J., Natarajan, N. and Srimathi, P. (2009). Performance of polycoated cluster bean
[Cyamopsis tetragonoloba (I.) taub.] seeds under different water holding capacities. Legume Res., 32 (2): 113-116.

13.Schneider, E. C. and Gupta, S. C. (1985). Corn emergence as influenced by soil temperature, matric potential and aggregate size distribution. Soil Sci. Soc. Am. J., 49: 415-422.

14.Taylor, A. G., Allen, P. S., Bennett, M. A., Bradford, K. J., Burris, J. S. and Misra M. K. (1998). Seed enhancement. Seed Sci. \& Technol., 8: 245-256.

15.Taylor, A. G. and Kwiatkowski, J. (2001). Polymer film coatings decrease water uptake and water vapour movement into seeds and reduce imbibitional chilling injury. http://www.seedquest.com/technology/ from/seedbiotics/may01/paper1.htm. 